\title{
High Gain and High Directive of Antenna Arrays Utilizing Dielectric Layer on Bismuth Titanate Ceramics
}

\author{
F. H. Wee, ${ }^{1}$ F. Malek, ${ }^{2}$ Farid Ghani, ${ }^{1}$ S. Sreekantan, ${ }^{3}$ and A. U. Al-Amani ${ }^{3}$ \\ ${ }^{1}$ School of Computer and Communication Engineering, Universiti Malaysia Perlis (UniMAP), 02600 Arau, Malaysia \\ ${ }^{2}$ School of Electrical Systems Engineering, Universiti Malaysia Perlis (UniMAP), 02600 Arau, Malaysia \\ ${ }^{3}$ School of Material and Mineral Resources, Universiti Sains Malaysia (USM), 11800 Gelugor, Malaysia
}

Correspondence should be addressed to F. H. Wee, weefwenhoon@gmail.com

Received 11 February 2012; Accepted 28 April 2012

Academic Editor: Hala A. Elsadek

Copyright ( 2012 F. H. Wee et al. This is an open access article distributed under the Creative Commons Attribution License, which permits unrestricted use, distribution, and reproduction in any medium, provided the original work is properly cited.

\begin{abstract}
A high gain and high directive microstrip patch array antenna formed from dielectric layer stacked on bismuth titanate (BiT) ceramics have been investigated, fabricated, and measured. The antennas are designed and constructed with a combination of two-, four-, and six-BiT elements in an array form application on microwave substrate. For gain and directivity enhancement, a layer of dielectric was stacked on the BiT antenna array. We measured the gain and directivity of BiT array antennas with and without the dielectric layer and found that the gain of BiT array antenna with the dielectric layer was enhanced by about $1.4 \mathrm{dBi}$ of directivity and $1.3 \mathrm{~dB}$ of gain over the one without the dielectric layer at $2.3 \mathrm{GHz}$. The impedance bandwidth of the BiT array antenna both with and without the dielectric layer is about $500 \mathrm{MHz}$ and $350 \mathrm{MHz}$, respectively, which is suitable for the application of the WiMAX $2.3 \mathrm{GHz}$ system. The utilization of BiT ceramics that covers about $90 \%$ of antenna led to high radiation efficiency, and small-size antennas were produced. In order to validate the proposed design, theoretical and measured results are provided and discussed.
\end{abstract}

\section{Introduction}

Currently, microstrip antennas with attractive features, such as low profile, light weight, and easy fabrication, are being widely used. Microstrip antennas also possess major shortcomings, such as narrow impedance bandwidth and low efficiency and gain, which seriously limit their application [1-3].

A recent pull for microwave components made of ceramic has drawn attention, especially antennas, due to their particular advantages for some applications, including zero conductor loss and low profile [4-9]. It has been shown experimentally that this kind of element can be an efficient radiator [1]. Experimental and theoretical evaluations of the ceramic antenna (CA) have been reported by many investigators [1-9].

In the search for new types of ceramic materials that achieve high permittivity and low loss, bismuth titanate (BiT), a new type of ceramic material, has been constantly developed, characterized, and implemented into the working electrical microwave model with the help of microwave simulator software and measurement hardware. In this study, we propose a novel CA with a new branching structure that uses ceramic material. This CA was designed with a rectangular cross-sectional area, referred to as "rectangular CA," and was executed with ceramic material that exhibits a permittivity value of 21 . The study of the BiT array antenna was designed for a target resonant frequency at $2.3 \mathrm{GHz}$. The design goal is to achieve an antenna reflectivity of less than $-10 \mathrm{~dB}$ to accommodate an efficient antenna feed with high radiation efficiency as well as a miniaturized antenna.

Increasing the gain of an antenna can be done in different ways. For example, one could use two or more evenly distributed antenna elements to put together an antenna array. Arrays have been successfully used for many years, but they still suffer from some fundamental drawbacks; the attached $100 \%$ copper plate is inevitably lossy and large in size $[7,8]$. On the other hand, arrays can provide useful features such as beam-steering capability, introduction of nulls in specific directions, and secondary lobe suppression by adjusting the phase and/or amplitude of signals feeding the individual 


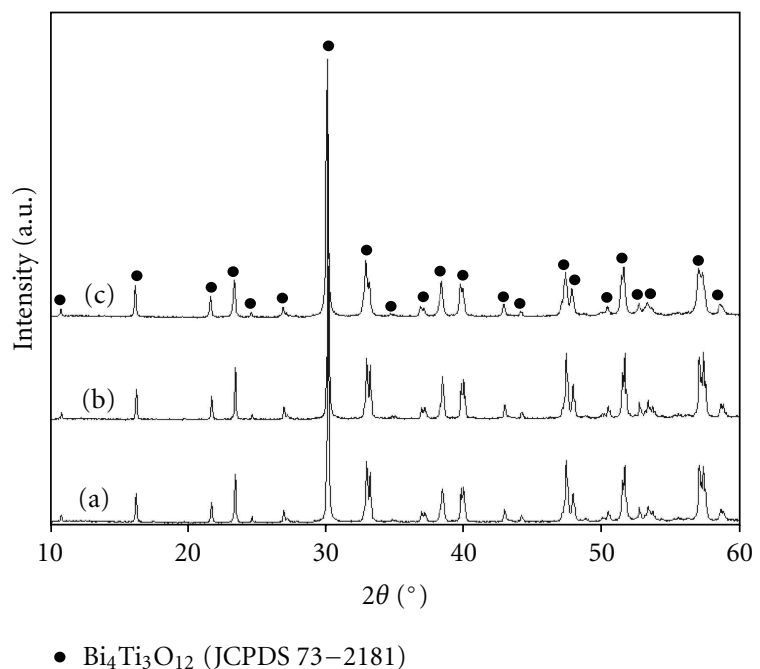

Figure 1: The XRD pattern of BiT powders at different calcination temperatures for 3 hours: (a) $900^{\circ} \mathrm{C}$, (b) $1000^{\circ} \mathrm{C}$, and (c) $1100^{\circ} \mathrm{C}$.

elements. Thus, the antenna presented in this paper is based on the increasing number of patch elements that utilize BiT ceramic materials instead of copper plate as the conventional antenna uses. The analysis of BiT fabrication and outcome are thus addressed.

\section{Bulk Bismuth Titanate (BiT) Analysis}

2.1. Sample Preparation. In the present study, the raw materials used consist of bismuth pentahydrate and titanium (IV) isopropoxide. Both raw materials were dissolved separately into a mixture of 2-methoxyethanol and acetylacetone. Ti solution and Bi solution were then formed from the raw material of bismuth pentahydrate and titanium (IV) isopropoxide, respectively. Both solutions were mixed and heated at $80^{\circ} \mathrm{C}$ to form a sticky gel and combusted to produce combusted powder. The calcination process was performed with high temperature and pressure of $750^{\circ} \mathrm{C}$ and $100 \mathrm{MPa}$, respectively to form a green body. Sintering was carried out at $1100^{\circ} \mathrm{C}$ for densification purposes.

2.2. Characterization. The X-ray diffraction (XRD) pattern in Figure 1 shows that crystallization of $\mathrm{BiT}$ was present as the temperature increased from $900^{\circ} \mathrm{C}$ to $1100^{\circ} \mathrm{C}$.

The peak in Figure 1 is centered at $2 \theta$ of $30^{\circ}$, which is the stable phase of pure BiT at high sintering temperature. This peak shows that the precursor had completely converted into the desired BiT compound.

The field emission scanning electron micrograph (FESEM) of BiT powder and the sintered pellet are shown in Figure 2, which shows that extensive grain growth has occurred, leading to platelet formation of the order of $200 \mathrm{~nm}$ to $10 \mu \mathrm{m}$. The platelets of BiT form a brick-wall-like structure by aligning on top of each other, as expected with less platelets damaged during sample preparation.

In our research, we also investigated the new aspect of the development and utilization of the Agilent $85070 \mathrm{~B}$

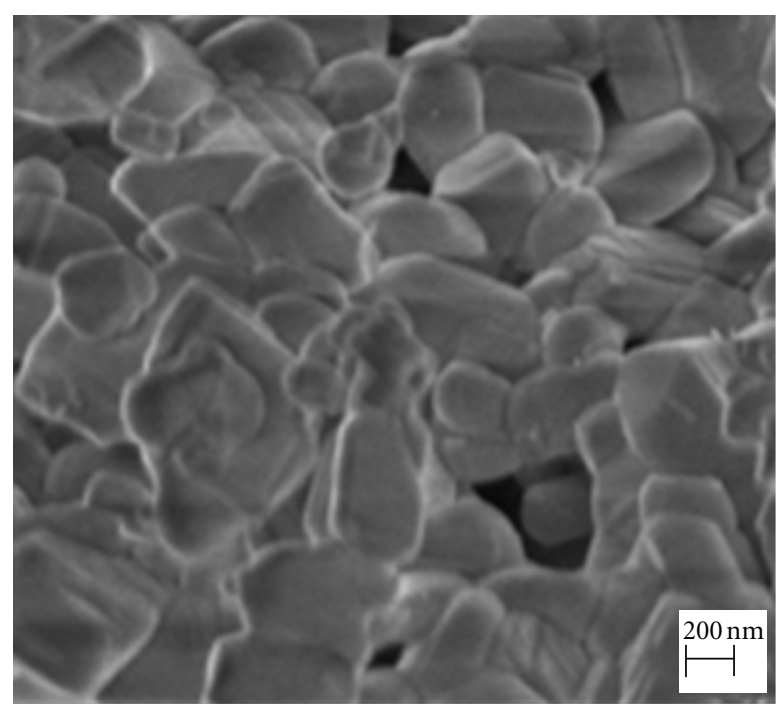

(a)

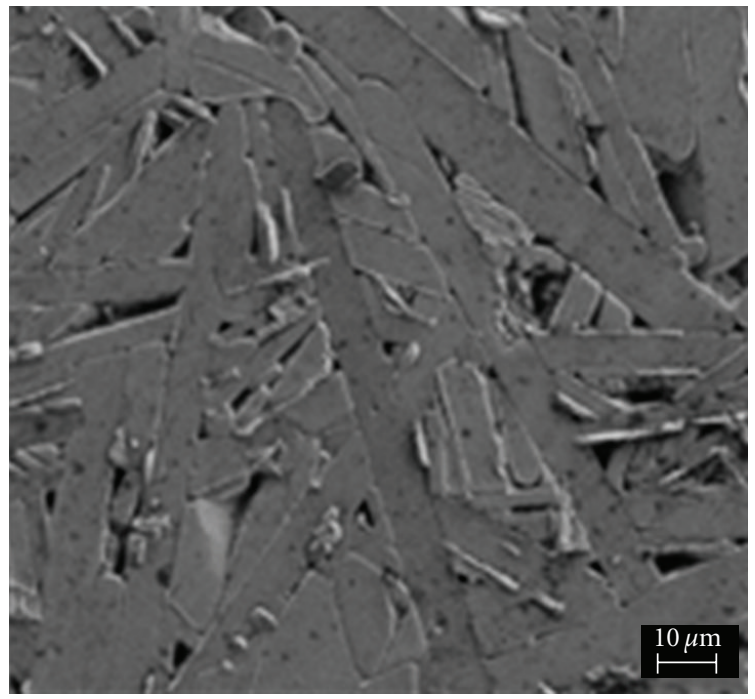

(b)

Figure 2: FESEM image of BiT: (a) calcined powder at $750^{\circ} \mathrm{C}$ for 3 hours and (b) sintered bulk ceramic at $1100^{\circ} \mathrm{C}$ for 3 hours.

high-temperature dielectric probe kit in measuring the permittivity of the BiT ceramic material. The frequency dependence of permittivity for BiT ceramic, $\varepsilon^{\prime}$, is shown in Figure 3 . As can be seen, the parameter has a strong dependence on frequency, with the permittivity decreasing as frequency increases; however, for the frequency range of 2 to $3 \mathrm{GHz}$, the permittivity of BiT was on average 21 , as shown in Table 1.

\section{BiT Array Antenna Design and Structures}

The proposed BiT array antennas have two layers, which are shown in Figure 4. The first layer is a transmission line, seen in Figure 4(a). Its optimal dimension is also presented in Figure 5. The transmission line uses copper, which is 


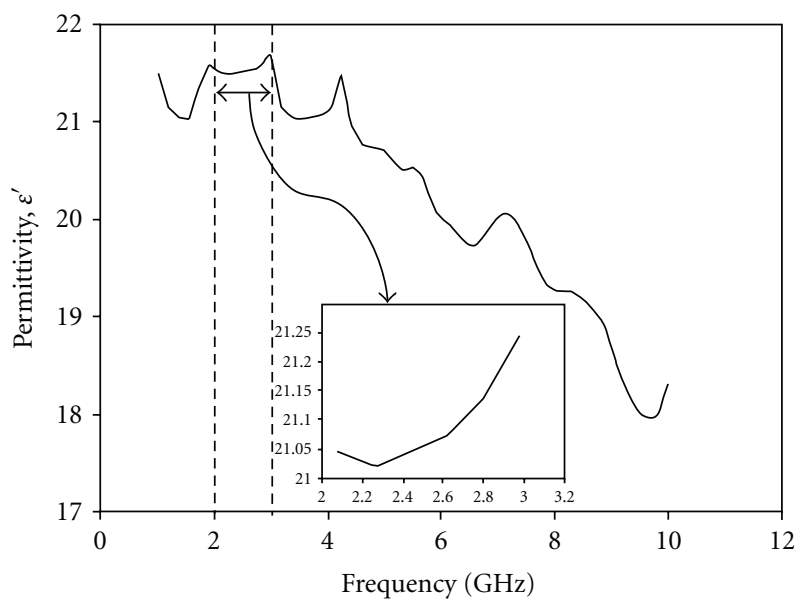

Figure 3: Permittivity of BiT ceramic at 1 to $10 \mathrm{GHz}$.

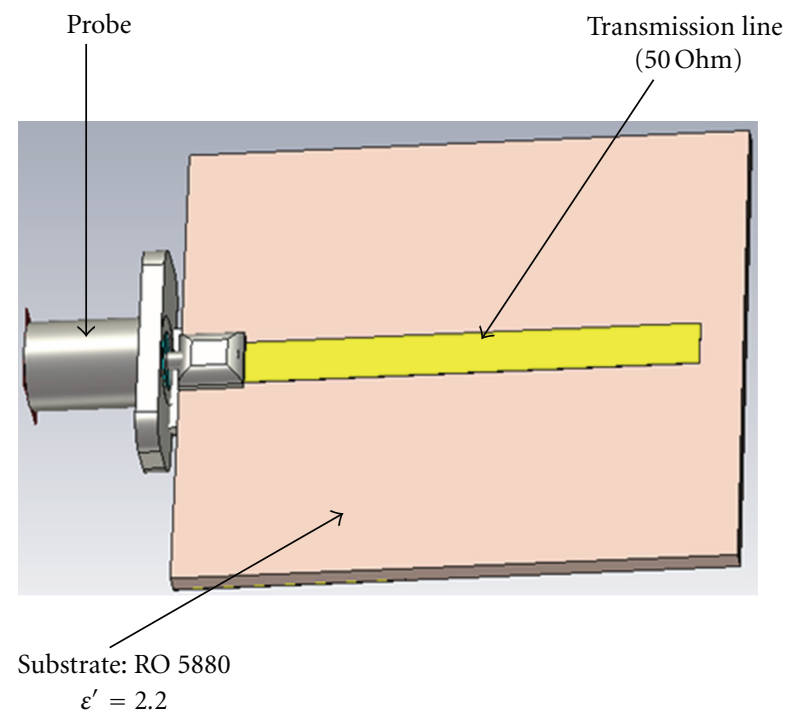

(a)

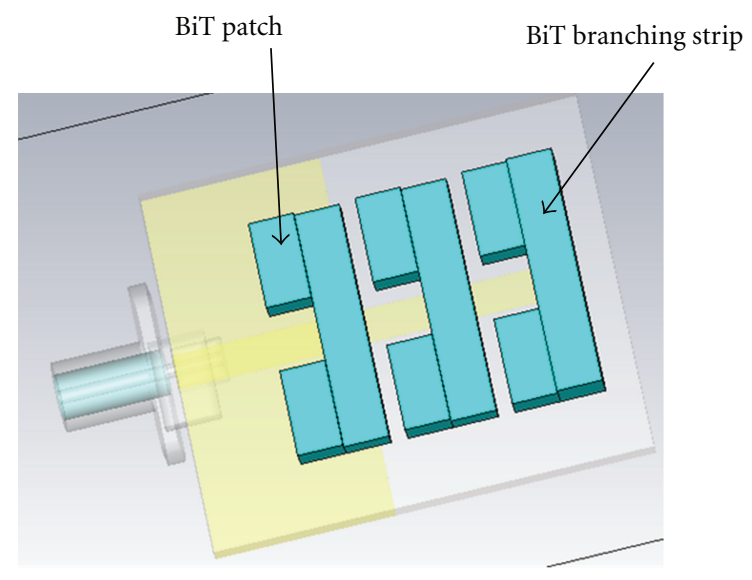

(b)

FIgURE 4: Configuration of the multilayers and its optimized dimensions, (a) first layer, (b) second layer.
TAble 1: Permittivity of BiT at frequency 2 to $3 \mathrm{GHz}$.

\begin{tabular}{lc}
\hline Frequency, GHz & Permittivity, $\varepsilon^{\prime}$ \\
\hline 2.0800 & 21.0469 \\
2.2600 & 21.0233 \\
2.4400 & 21.0447 \\
2.6200 & 21.0761 \\
2.8000 & 21.1385 \\
2.9800 & 21.2498 \\
\hline
\end{tabular}

a conducting material, in order to function as a feeding channel.

For the second layer of this investigation, the effectiveness of BiT was determined as a radiating element itself. The novelty of this design is the BiT ceramics with high permittivity and low loss. The attenuation due to the conductor can be simplified as:

$$
\alpha_{c}=\frac{8.68 R_{s}}{\mathrm{WZ}}(\mathrm{dB} / \mathrm{cm})
$$

where $R_{s}$ is the surface resistivity and is given by:

$$
\begin{gathered}
R_{s}=\sqrt{\frac{\omega \mu_{0}}{2 \sigma_{c}}}, \\
\alpha_{c}=\frac{8.68}{\mathrm{WZ}} \sqrt{\frac{\omega \mu_{0}}{2 \sigma_{c}}}(\mathrm{~dB} / \mathrm{cm}) .
\end{gathered}
$$

The attenuation due to dielectric material can be given by the following formula [2]:

$$
\alpha_{d}=\frac{\omega}{2} \sqrt{\left(\mu_{0} \varepsilon_{0} \varepsilon_{r}\right) \tan \delta},
$$

where

$$
\begin{gathered}
\omega=2 \pi f_{r}, \\
\tan \delta=\frac{\varepsilon_{r}^{\prime \prime}}{\varepsilon_{r}^{\prime}}, \\
\varepsilon_{r}=\varepsilon_{r}^{\prime}-i \varepsilon_{r}^{\prime \prime} .
\end{gathered}
$$

The reflection loss of BiT is much smaller compared to that of conventional copper, which is often used in antenna application. At $2.30 \mathrm{GHz}$, reflection loss for BiT is $0.060 \mathrm{~dB} /$ $\mathrm{cm}$, while for copper, the reflection loss achieves up to $1.028 \mathrm{~dB} / \mathrm{cm}$. The proper sizes, positions, and shapes were added to the second layer of antenna as shown in Figure 4(b).

Three types of BiT array antenna designs had been carried out in this study. There are two, four, and six elements of BiT ceramic in array antenna that had different respective dimensions. The geometry of the proposed BiT array antennas is shown in Figure 5, which presents both the front and side views. The antenna is realized on a low-loss RT/ Duroid 5880 commercial microwave substrate from Roger Corporation (http://www.rogerscorp.com/), with a permittivity of 2.20, where the BiT branching strips and patches are of 21 in permittivity value. The transmission line width is 


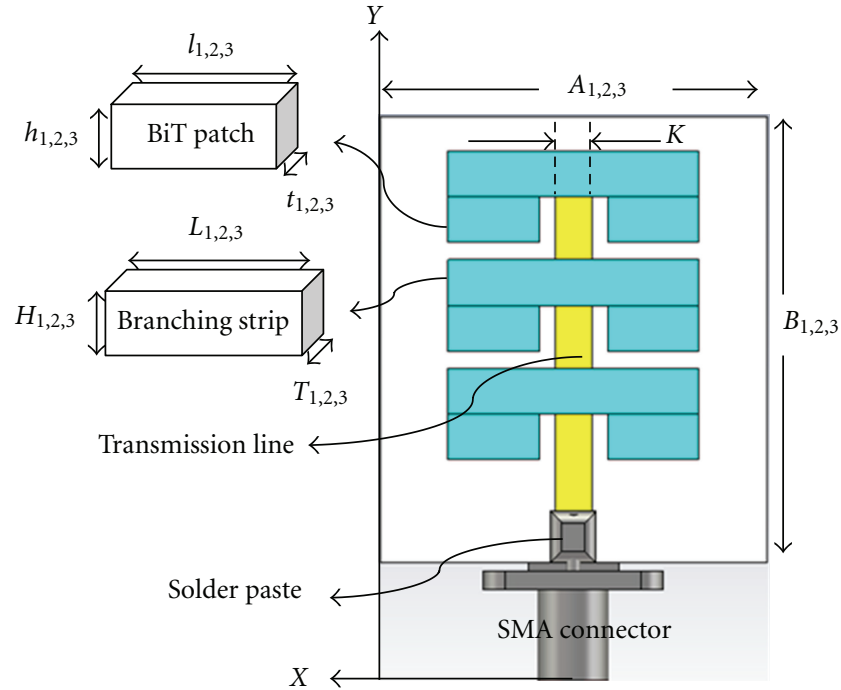

(a)

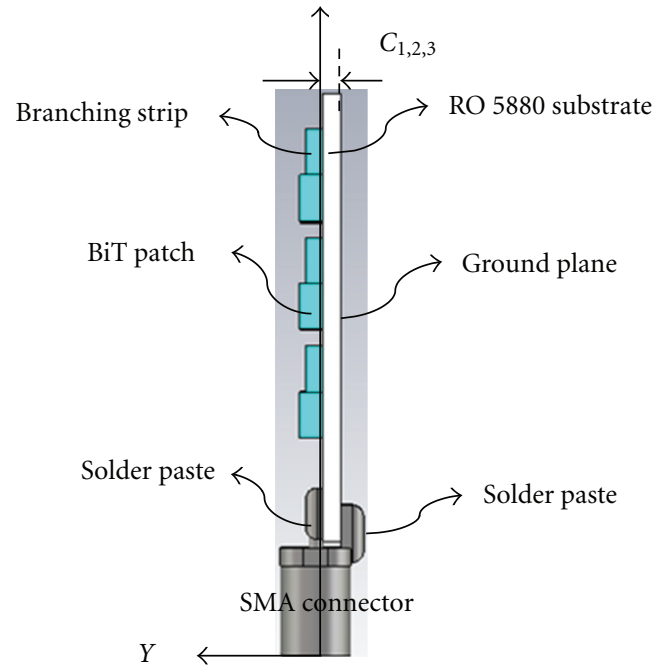

(b)
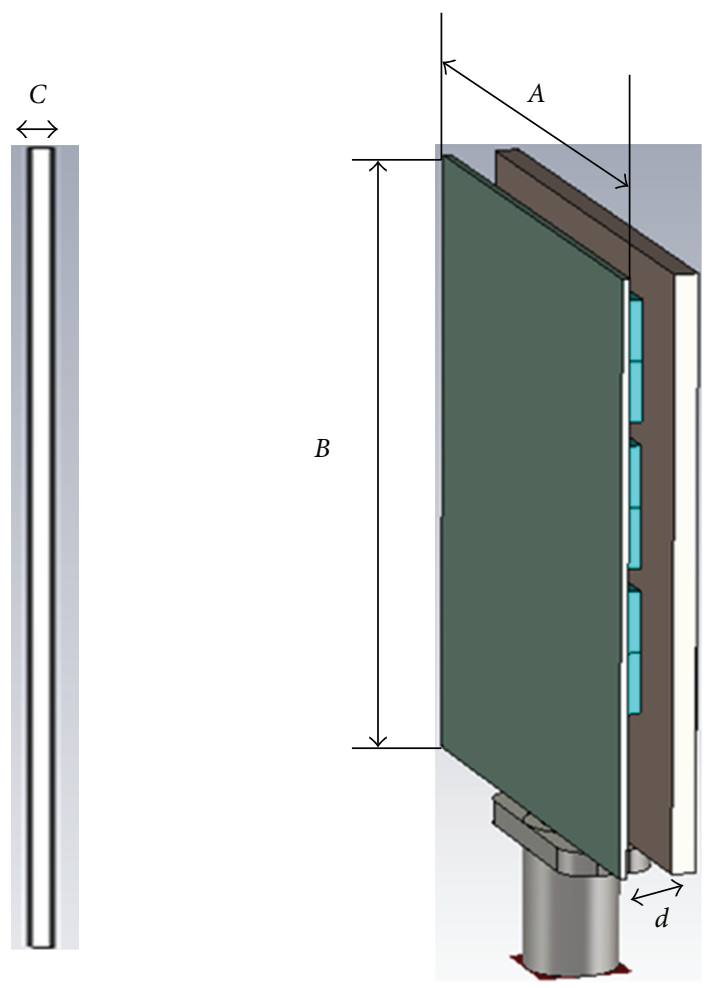

(c)

Figure 5: Geometry layout of proposed BiT array antenna (a) front (b) side views (c) stacked dielectric layer.

optimized to $K=4.6 \mathrm{~mm}$ in order to achieve the best $50 \Omega$ input impedance matching.

The number of elements and the wavelength of the ceramic array antenna, $\lambda_{g}$ were approximated using:

$$
\lambda_{g}=\frac{\lambda_{0}}{\sqrt{n \varepsilon^{\prime}}}
$$

where $\lambda_{g}$ is the guided wavelength in CA, $\lambda_{0}$ is the freespace wavelength, $\varepsilon^{\prime}$ is the dielectric constant of the ceramic, and $n$ denotes the number of ceramic elements. Hence, (5) shows that the higher the number of ceramic elements, the smaller the size of the array antenna obtained. In addition, optimization was also carried out for the BiT ceramic dimensions in order to gain the best antenna performance.

The optimal antenna size for the quantity of two elements $\operatorname{BiT}$ is $A_{1}=30 \mathrm{~mm}, B_{1}=33 \mathrm{~mm}$, and $C_{1}=1.6 \mathrm{~mm}$. The parameter of BiT branching strip and patches are $H_{1}=2.5 \mathrm{~mm}$, $L_{1}=27 \mathrm{~mm}, T_{1}=1 \mathrm{~mm}$ and $h_{1}=2.5 \mathrm{~mm}, l_{1}=4.5 \mathrm{~mm}$, and $t_{1}=0.8 \mathrm{~mm}$, respectively. Next, four elements of BiT were attached on the RT/Duroid 5880 substrate board with each 


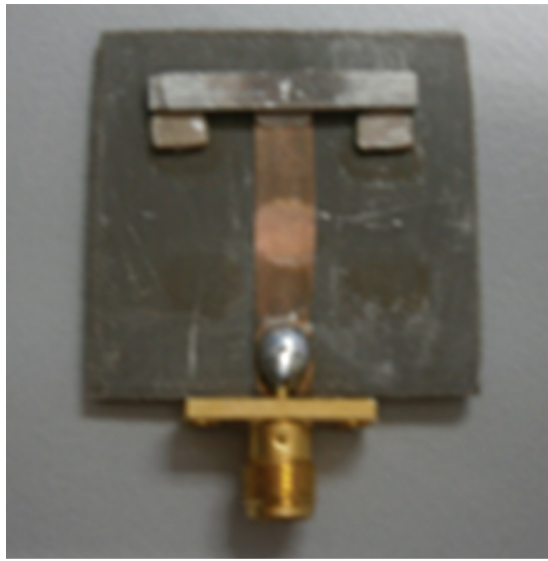

(a)

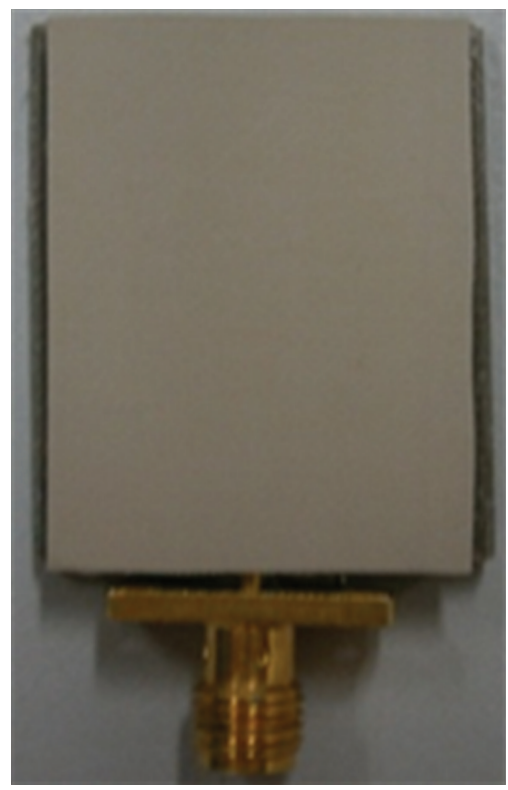

(i)

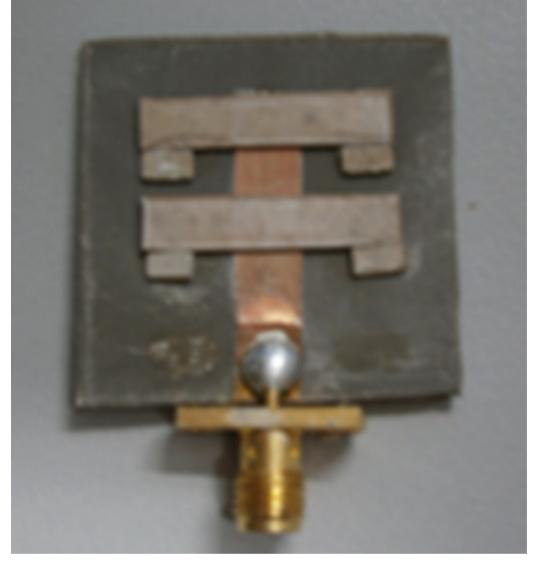

(b)

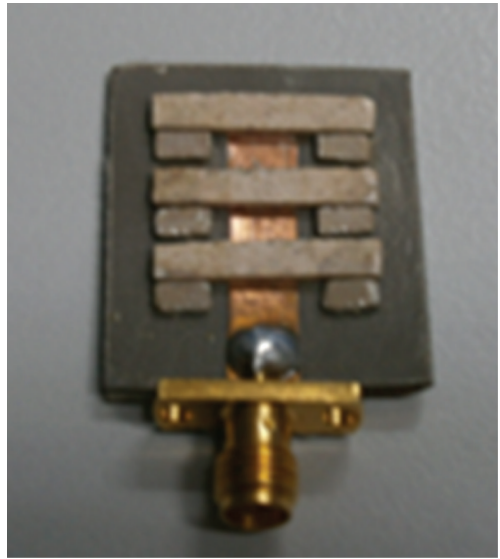

(c)

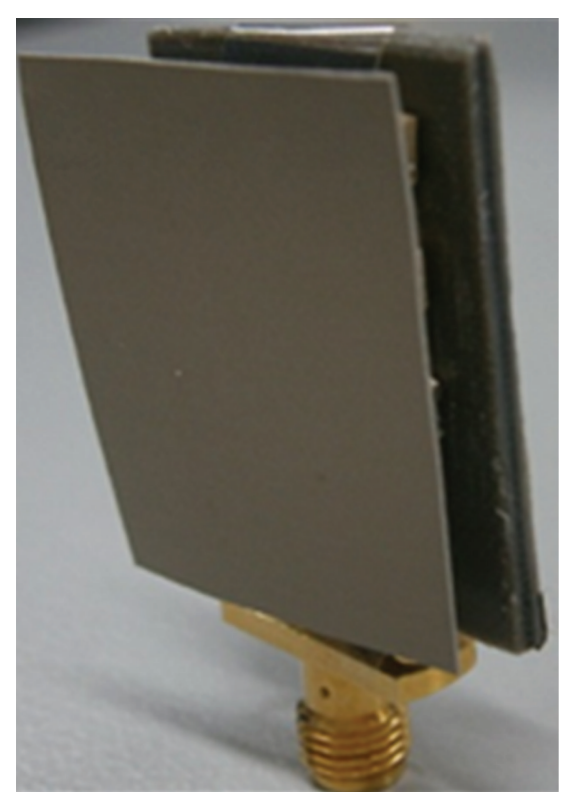

(ii)

(d)

Figure 6: Photograph of fabricated BiT array antennas (a) two BiT ceramic elements (b) four BiT ceramic elements (c) six BiT ceramic elements (d) dielectric layer (i) front view (ii) perspective view.

edge of the BiT patch size being $h_{2}=2.5 \mathrm{~mm}, l_{2}=3.5 \mathrm{~mm}$, and $t_{2}=0.8 \mathrm{~mm}$; the length, $l_{2}$, had been reduced $33 \%$ from the two elements of BiT antenna, while the BiT array antenna sizes for the four elements are $A_{2}=27 \mathrm{~mm}, B_{2}=29 \mathrm{~mm}$, and $C_{2}=1.6 \mathrm{~mm}$, which are on average $3 \mathrm{~mm}$ smaller than the two elements of BiT antenna. Branching strip dimensions were optimized to $H_{2}=2.5 \mathrm{~mm}, L_{2}=25 \mathrm{~mm}$, and $T_{2}=$ $1 \mathrm{~mm}$ to obtain good radiation properties. Lastly, the size of the six-element BiT antenna can be observed as the smallest compared to both the two- and four-BiT elements of the BiT array antenna, which are $A_{3}=22 \mathrm{~mm}, B_{3}=25 \mathrm{~mm}$, and $C_{3}=1.6 \mathrm{~mm}$, and each of the BiT patch element sizes is $h_{3}=$ $2.5 \mathrm{~mm}, l_{3}=3 \mathrm{~mm}, t_{3}=0.8 \mathrm{~mm}$, while the BiT branching strip is $H_{3}=2.5 \mathrm{~mm}, L_{3}=20 \mathrm{~mm}$, and $T_{3}=1 \mathrm{~mm}$. Besides the modeling design, the prototype of the BiT array antennas were fabricated and measured, as can be seen in Figure 6 .
This aimed to ensure a good agreement in performance between them.

In designing the BiT array antenna and the dielectric layer stacked as well, one must consider the possibility of high loss performed by the antenna. Numerical simulation shows high levels of the conduction loss and power loss with the utilization of the metallic structure on the antenna. Therefore, BiT array antennas were designed with low-loss BiT elements present with negligible metallic loss in antenna structure to reduce the loss factor that will lead to low antenna performance.

\section{Dielectric Layer Design}

To overcome the disadvantages of low gain and directivity, some papers have proposed gain enhancement methods 


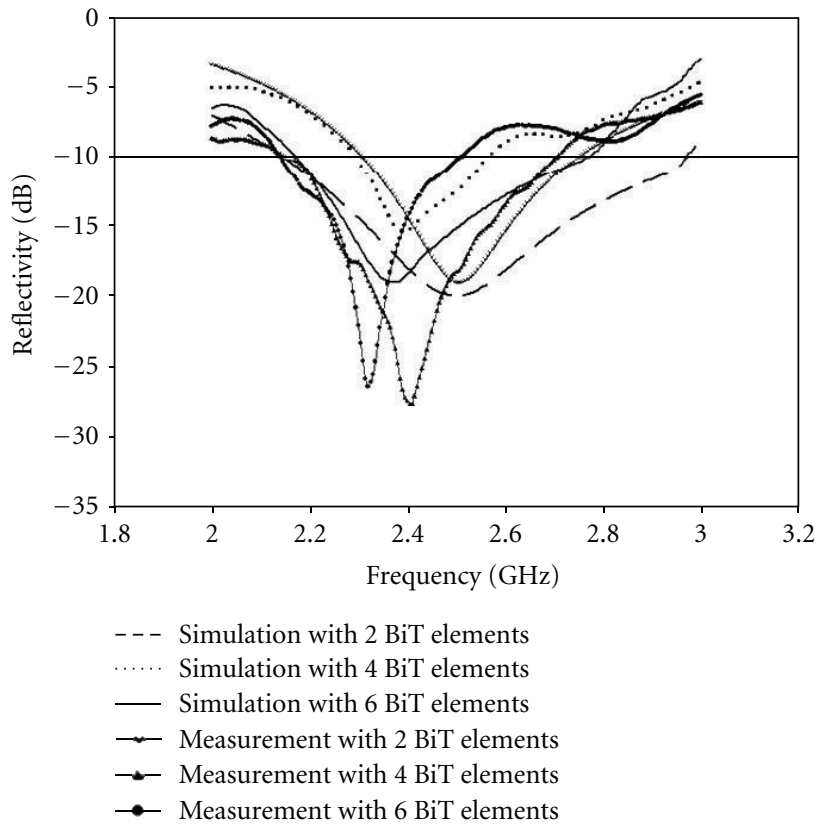

(a)

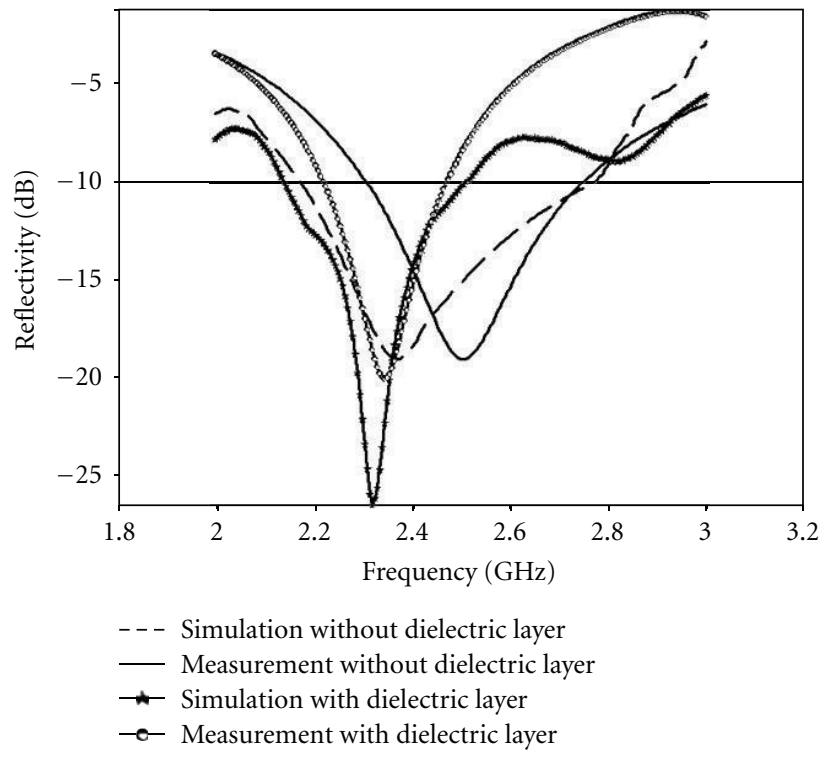

(b)

Figure 7: Simulated and measured reflectivity of the proposed BiT array antennas (a) two-, four-, and six-BiT element array antenna (b) with and without the dielectric layer.

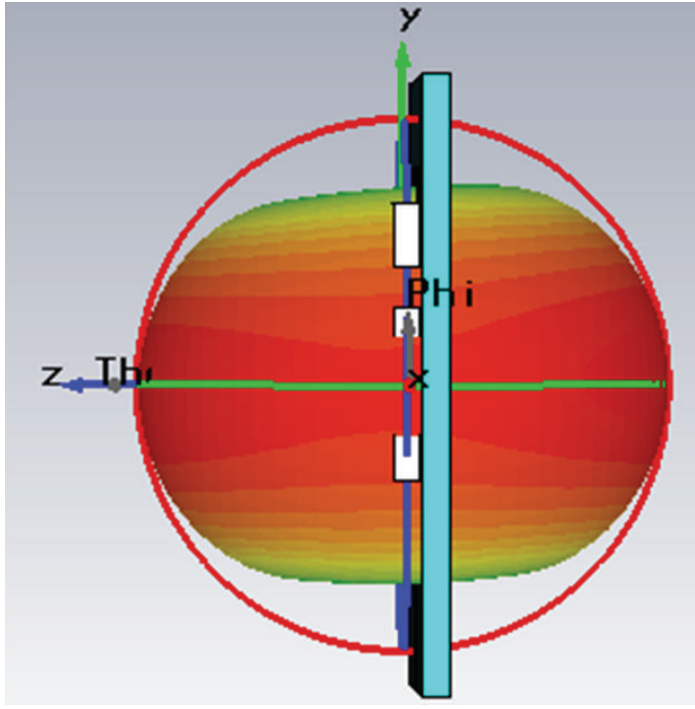

(a)

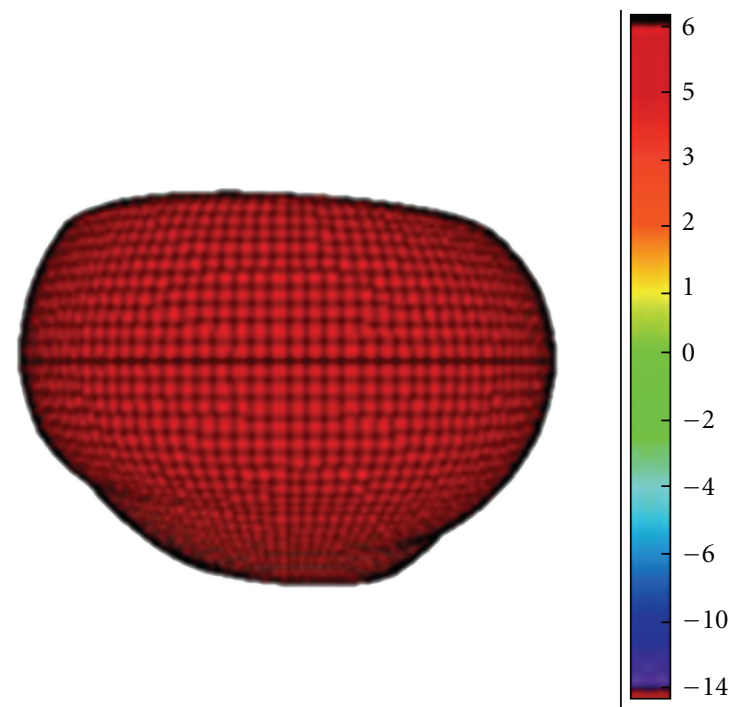

(b)

Figure 8: Radiation pattern of BiT in 3D view (a) simulated (b) measured.

using multiple dielectrics [7-9]. It has been reported that high gain and high directivity can be achieved if the substrate and dielectric layer are used appropriately [9].

In order to obtain high gain and directivity of this antenna, a suitable dielectric layer of appropriate thickness and loss tangent is chosen. Thinner dielectrics which help to reduce weight also able to reduce the surface wave losses. The dielectric's dielectric constant, $\varepsilon^{\prime}$, plays an important role similar to that of the dielectric's thickness. A low value of $\varepsilon^{\prime}$ for the dielectric will increase the fringing field of the patch and thus the radiated power. A low-loss tangent reduces the dielectric loss and therefore increases the antenna efficiency. Thus, the dielectric parameters so chosen are Tarconic CER10 , with a thickness of $0.5 \mathrm{~mm}$, permittivity of $\varepsilon^{\prime}=10$, and a loss tangent $\tan \delta=0.0004$.

The dielectric with dimensions of $R=25 \mathrm{~mm}, A=$ $20 \mathrm{~mm}$, and $C=0.5 \mathrm{~mm}$ as in Figure 5(c) is placed above the radiating patch BiT elements at a distance of $d=5 \mathrm{~mm}$, 
TABLe 2: Gain, directivity, and radiation efficiency of BiT Array Antennas.

\begin{tabular}{lcccc}
\hline \multirow{2}{*}{ Parameters $(2.3 \mathrm{GHz})$} & \multicolumn{3}{c}{ Number of BiT element } & BiT array antenna with dielectric layer \\
\hline Gain $(\mathrm{dB})$ & 2 elements & 4 elements & 6 elements & 8.920 \\
Directivity (dBi) & 6.559 & 7.188 & 7.514 & 9.230 \\
Radiation Efficiency (\%) & 7.174 & 7.697 & 7.913 & 96.6 \\
\hline
\end{tabular}

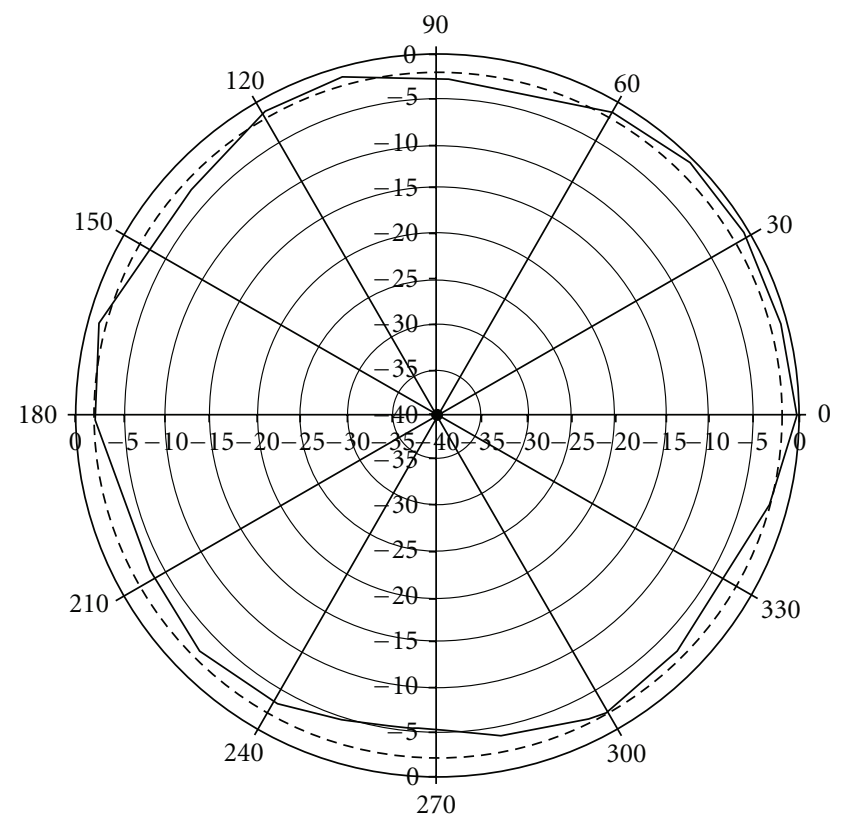

- - Simulation

— Measurement

(a)

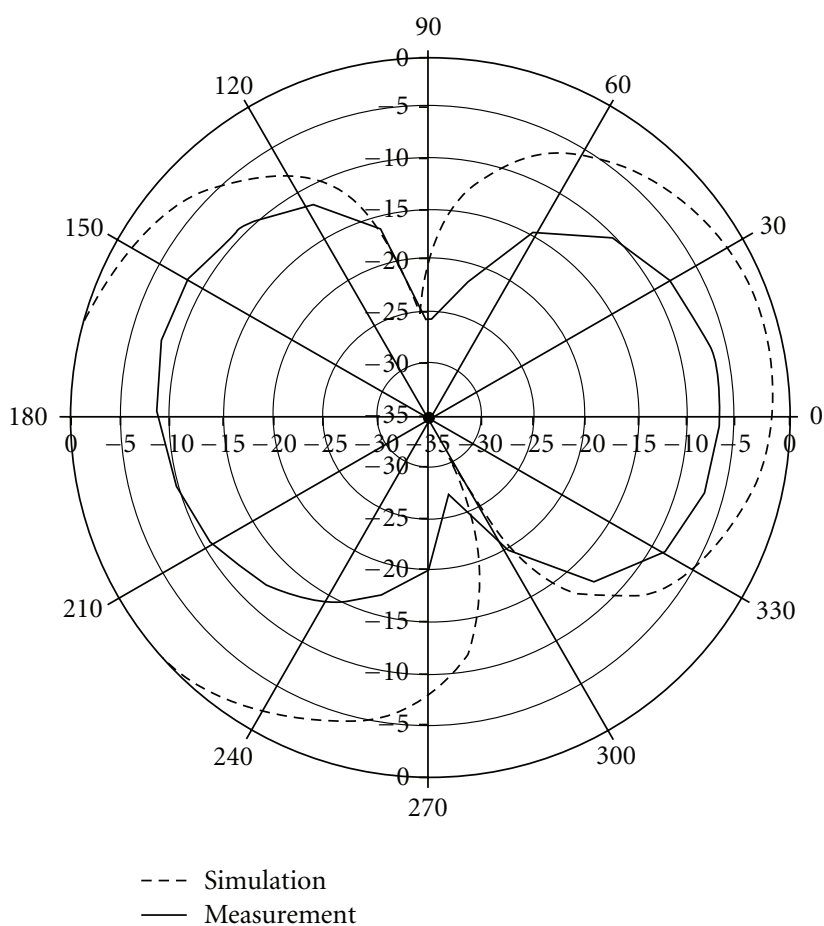

(b)

Figure 9: Simulated and measured 2D radiation plot for a six-BiT element array antenna at $2.30 \mathrm{GHz}$ (a) horizontal plane (b) vertical plane.

which is the optimum distance at which to obtain high gain and high directivity. This paper experimentally investigates the effect of a dielectric layer as the superstrate layer for high gain and high directivity on the six elements of BiT array antenna and the comparison between BiT array antenna with and without the dielectric layer.

\section{Results and Discussion}

The performance of the simulated BiT array antennas with and without the dielectric layer is analysed using Computer Simulation Technology (CST) Microwave Studio, while the fabricated BiT array antennas with and without the dielectric layer were tested using a network analyser and a near-field test facility. Figure 7(a) shows a graph of reflectivity of two-, four-, and six-element BiT array antenna, which had been converted into log magnitude in $\mathrm{dB}$.

The simulation and measurement results show that the reflectivity is the lowest at $-27 \mathrm{~dB}$ at the centre frequency of $2.40 \mathrm{GHz}$ for BiT array antenna without the dielectric layer. However, with the stackedness of the dielectric layer on BiT array antennas, the frequency had been shifted to a lower frequency of $2.30 \mathrm{GHz}$. The frequency shift is also occurring when the number of BiT elements increases from a twoelement to a six-element array antenna, as can be seen in Figure 7(b). This condition occurs due to the capacitive effects of placing the dielectric over the antenna.

The operating bandwidth of the proposed BiT array antennas for both with and without the dielectric layer was found to be about $350 \mathrm{MHz}$ and $500 \mathrm{MHz}$, respectively, which is compatible with the specification of the WiMAX system. Overall, good agreements were found between the simulation and measurement results, although there was slight discrepancy between them, believed to be due to the environmental effect and mechanical tolerance, which were neglected in our simulations.

The simulated and measured radiation patterns in 3D view are observed in Figure 8. There were no top and bottom lobes at the rear end of the radiation pattern whilst the main directivity was directed at the vertical plane, which formed an omnidirectional signal level in the $\mathrm{H}$-plane. The $\mathrm{H}$ plane plays an important role as this parameter determines 
the point of strongest signal, thus avoiding signal redundancy and interference with other antennae radiating at the same plane.

Figure 9 shows the radiation pattern of a six-element BiT array antenna in 2D view, which was analyzed in vertical plane (XZ, YZ) and in horizontal plane (XY) at $2.30 \mathrm{GHz}$. This antenna provides a 360-degree coverage signal, which is in all directions (horizontally) for two-way communication.

From Table 2, the gain of the six-element BiT array antenna, in radiation patterns, with dielectric layer does exhibit $8.920 \mathrm{~dB}$ and $9.230 \mathrm{dBi}$ of gain and directivity, respectively. The simulation results show that the gain of the 4-element BiT array antenna has improved greatly compared to the common antenna.

\section{Conclusions}

In this paper, the application of rectangular bismuth titanate (BiT) material as a ceramic antenna (CA) in array form, which composed of two-, four-, and six-element BiT as well as a stacked dielectric layer, were investigated and successfully carried out. The antenna exhibited acceptable bandwidths, reflectivity, and radiation characteristics for WiMAX application. As a result, we find that $\mathrm{BiT}$ array antennas are attractive and can be practical for various systems. By taking into account all of the details of each component, including the dimensions and permittivity value, the antennas did perform up to expectation when the number of BiT element increased at the WiMAX band. In future work, bismuth titanate (BiT) can be investigated for other types of antenna in order to determine the level of performance improvement in term of bandwidth particularly in an optimized radiation pattern. In addition, antenna enhancement can be done by adjusting the distance $d$, and the resonance condition for high gain as well as high directivity can be obtained.

\section{References}

[1] M. F. Ain, S. I. S. Hassan, J. S. Mandeep et al., "2.5 GHZ batio3 dielectric resonator antenna," Progress in Electromagnetics Research, vol. 76, pp. 201-210, 2007.

[2] C. A. Balanis, Antenna Theory: Analysis and Design, Wiley Interscience, Hoboken, NJ, USA, 3rd edition, 2005.

[3] S. Prabhu, J. S. Mandeep, and S. Jovanovic, "Microstrip bandpass filter at $\mathrm{S}$ band using capacitive coupled resonator," Progress in Electromagnetics Research, vol. 76, pp. 223-228, 2007.

[4] R. K. Mongia, A. Ittipiboon, and M. Cuhaci, "Measurement of radiation efficiency of dielectric resonator antennas," IEEE Microwave and Guided Wave Letters, vol. 4, no. 3, pp. 80-82, 1994.

[5] A. A. Kishk, X. Zhang, A. W. Glisson, and D. Kajfez, "Numerical analysis of stacked dielectric resonator antennas excited by a coaxial probe for wideband applications," IEEE Transactions on Antennas and Propagation, vol. 51, no. 8, pp. 1996-2006, 2003.

[6] A. A. Kishk, "Wide-band truncated tetrahedron dielectric resonator antenna excited by a coaxial probe," IEEE Transactions on Antennas and Propagation, vol. 51, no. 10, pp. 2913-2917, 2003.

[7] M. T. Lee, K. M. Luk, K. W. Leung, and M. K. Leung, "Small dielectricresonator antenna," IEEE Transactions on Antennas and Propagation, vol. 50, pp. 1485-1487, 2002.
[8] J. Clerk Maxwell, A Treatise on Electricity and Magnetism, vol. 2, Clarendon, Oxford, UK, 3rd edition, 1892.

[9] S. Sreekantan, A. F. M. Noor, Z. A. Ahmad, R. Othman, and A. West, "Structural and electrical characteristic of crystalline barium titanate synthesized by low temperature aqueous method," Journal of Materials Processing Technology, vol. 195, no. 1-3, pp. 171-177, 2008. 

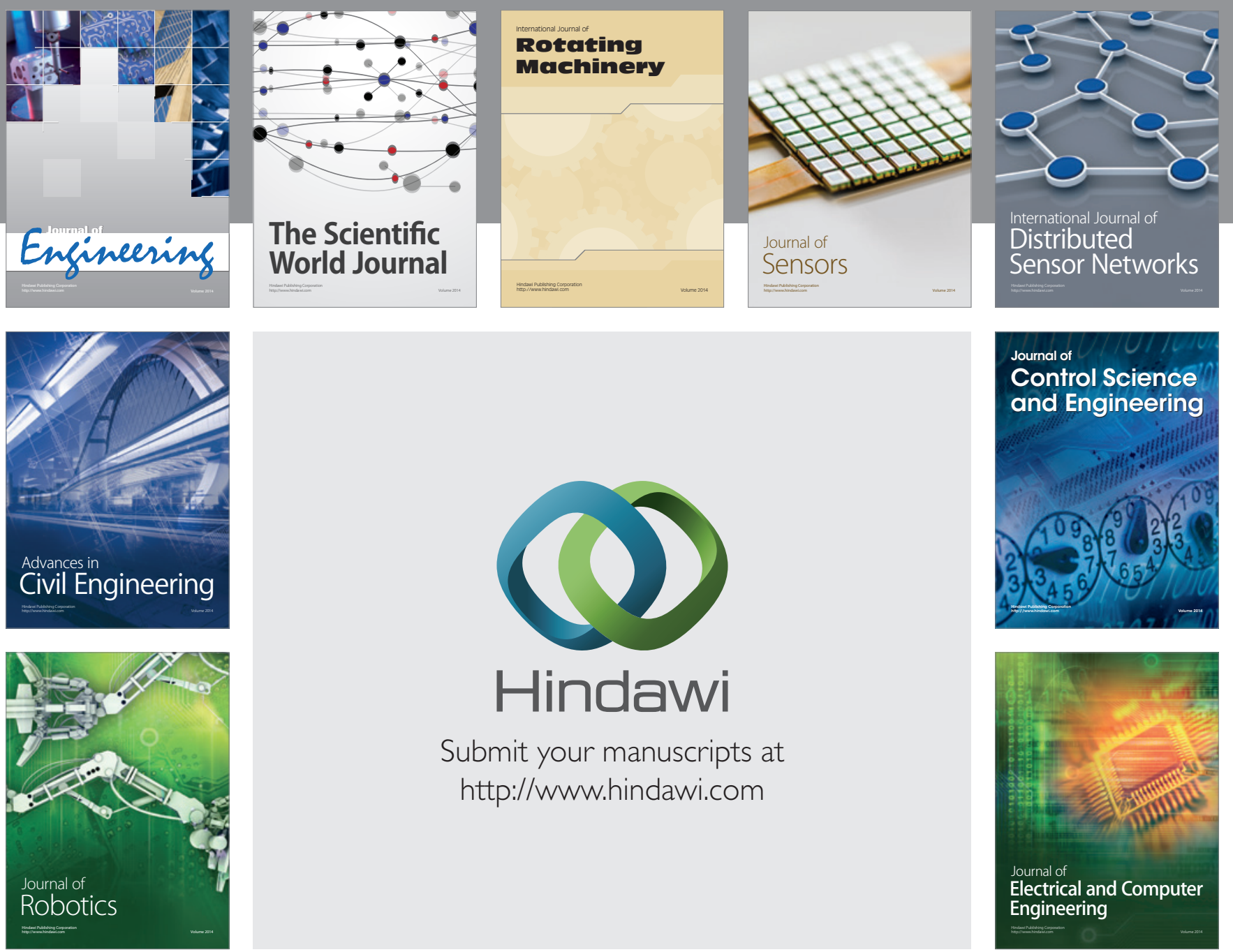

Submit your manuscripts at

http://www.hindawi.com
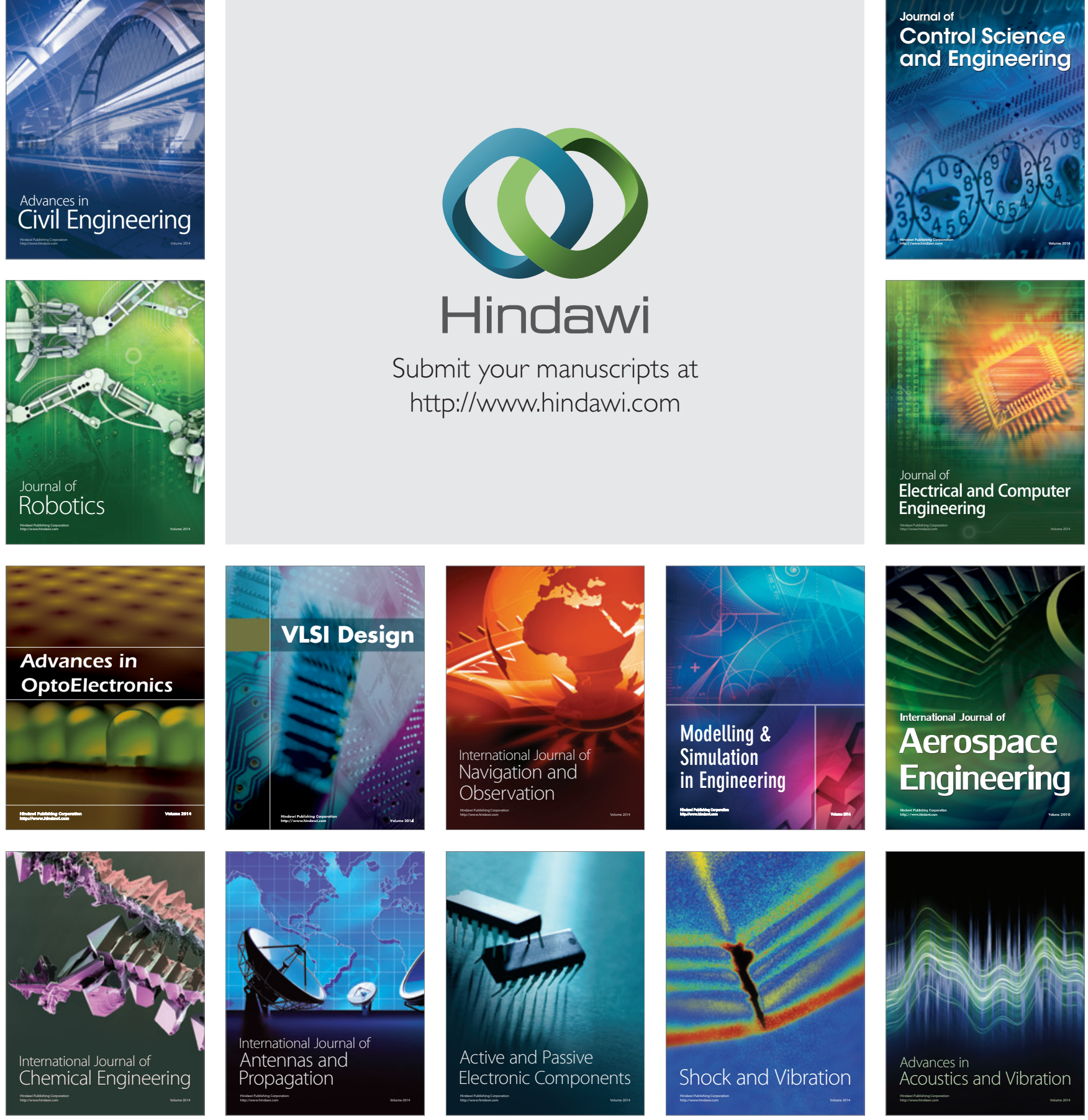